\title{
Clínica do trauma e narRativa do SOFRIMENTO \\ http://dx.doi.org/10.1590/1984-0292/1330
}

\author{
César Pessoa Pimentel
}

Universidade Federal do Rio de Janeiro, Rio de Janeiro, RJ, Brasil

\section{ReSUMo}

Pretende-se analisar o nexo entre trauma e narração. Nos concentraremos no arco histórico que liga a categoria de "sindrome do sobrevivente", popular na década de 1960, até o reconhecimento da categoria de "Transtorno de Estresse pós-traumático" em 1980. O tema é analisado pela leitura de autores contemporâneos ligados à genealogia foucaultiana, como Ruth Leys, Ian Hacking e Paulo Vaz. Conclui-se que essa nova concepção do trauma modifica a relação entre trauma e narração, fazendo com que a experiência traumática seja destacada em narrativas midiáticas, literárias e cinematográficas como evidencia de atrocidades externas e independentes do sujeito. Em outros termos, tendem a realçar a fragilidade humana.

Palavras-chave: trauma; sindrome do sobrevivente; narrativa; subjetividade.

\section{Clinic of Trauma and narrative of Suffer}

\begin{abstract}
It is intended to analyze the link between trauma and narration. We will focus on the historic arch that connects the category of "survivor syndrome", popular in the 1960s, to a recognition of the category of "Posttraumatic Stress Disorder" in 1980's. The theme is analyzed by reading contemporary authors linked to Foucault's genealogy, as Ruth Leys, Ian Hacking and Paulo Vaz. It is concluded that this new conception of trauma modifies the relationship between trauma and narrative, making the traumatic experience is highlighted in media, literary and cinematic narratives as evidence of atrocities external and independent of the subject. In other words, tend to emphasize human frailty.
\end{abstract}

Keywords: trauma; survivor syndrome; narrative; subjectivity.

\footnotetext{
^Endereço para correspondência: Universidade Federal do Rio de Janeiro, Reitoria, Centro de Filosofia e Ciências Humanas. Avenina Pasteur, 250 - Urca. 22290240 - Rio de Janeiro, RJ Brasil.E-mail: cesar.pim@hotmail.com
} 
O objetivo do artigo é analisar as implicações de uma certa concepção de trauma psicológico, elaborada dentro da clínica psiquiátrica norte-americana, sobre a narração do sofrimento de indivíduos e coletividades. Nos concentraremos no arco histórico que liga a categoria de "síndrome do sobrevivente", elaborada pelo psiquiatra Robert Jay Lifton (2005) na década de 1960, até a inclusão da categoria de "Transtorno de Estresse pós-traumático" em 1980 no manual de psiquiatria americana DSM-III (APA, 1980).

Embora o campo estético não seja visado diretamente, é inevitável que o tema da narrativa conduza a experiência estéticas que buscam dar sentido ao sofrimento traumático, sejam estas literárias, advindas das artes plásticas ou do cinema. Por outro lado, a sintomatologia da experiência traumática é cercada de metáforas sobre imagens visuais que inundam o aparato psíquico (HACKING, 2000). De acordo com o psicanalista Ernst Simmel (apud SELIGMANN-SILVA, 2009 , p. 1), a técnica de produção de imagens se assemelha à experiência traumática, que seria "uma estampa fotograficamente exata"

Conceituamos "trauma psicológico" no sentido empregado pelo filósofo Ian Hacking (2009). Não se trata de uma realidade inscrita desde sempre na natureza humana, mas de um tipo de enunciado sobre essa natureza capaz de modificar as ações e o significado que os indivíduos constroem sobre seu sofrimento. Isso não significa dizer que antes do surgimento do termo, pessoas não sofressem e apresentassem sintomas tais como os descritos posteriormente pela psicanálise, psicologia do desenvolvimento e psiquiatria. No entanto, a reunião desses sintomas, a explicação sobre sua origem e as possibilidades de modificá-los é própria a um momento recente da História das sociedades industriais, podendo ser recuada ao século XIX (HACKING, 2000; 2009). Quando isso é realizado dentro da clínica, os indivíduos passam a ser categorizados de diversas formas: responsáveis ou não pelos seus atos, simuladores ou enfermos, as mais lúcidas das testemunhas ou as mais atordoadas (FASSIN; RECHTMAN, 2009).

Nesse sentido, a clínica do trauma dentro do presente recorte histórico é visada como condição de possibilidade para a emergência de uma figura da subjetividade: a vítima de situações desumanas na qual permanece um resto de humanidade. No período compreendido pela invenção e uso das categorias de "Síndrome do sobrevivente" e "Transtorno pós-traumático", essa testemunha, conforme veremos, na medida em que se torna cada vez mais fidedigna e habilitada para narrar se torna cada vez mais passiva frente a acontecimentos disruptivos. ${ }^{1}$

A hipótese com que iremos trabalhar, baseada nos trabalhos de Ian Hacking (2000), Ruth Leys (2008), Fassin e Rechtman (2009) e Paulo Vaz (2011), estabelece o encontro da clínica americana do trauma e movimentos sociais entre as décadas de 1960 e 1980 como condição de possibilidade para uma mudança fundamental no nexo entre trauma e narração. A crítica literária Beatriz Sarlo (2006) que aborda o mesmo tema no campo das ditaduras latino-americanas, sublinha que antes da Segunda Guerra, a dificuldade em narrar eventos traumáticos aparece frequentemente realçada em textos como "O narrador" de Walter Benjamin. Benjamin (2008) afirma que após a Primeira Guerra os homens voltaram 
silenciosos, sem muito a dizer sobre o que viveram, apesar da intensidade dos acontecimentos ao seu redor. Da década de 1960 em diante, a relação entre trauma e narração se reconfigura: não importa se a memória traumática é nebulosa, os que sobrevivem a condições limite serão testemunhas do inacreditável. Portanto, o silêncio deve ser rompido. Tentaremos mostrar que boa parte dessa reconfiguração toma impulso a partir da clínica psiquiátrica norte-americana do trauma, da qual Robert Lifton (2005) é importante representante. O autor, entrevistou e registrou os sobreviventes de Hiroshima, ao final teorizando sobre a culpa da vítima como sintoma de ocorrência de situações de extrema violência.

Dessa interpretação clínica e outras que a seguirão, sobreveio uma importância dada à memória, narração e ao trauma em campos geográficos e temas muito mais amplos do que os originais. Como apontam Fassin e Rechtman (2009), a partir da publicação do DSM-III, a noção de trauma se generaliza, sendo aplicada hoje a situações que atravessam as fronteiras entre natureza e cultura. O evento traumático é necessário para o diagnóstico, mas sua definição acolhe eventos tanto intencionais, como abuso sexual e assassinato, como não intencionais, a exemplo de Tsunamis, enchentes e terremotos.

Segundo a linha de investigação dos autores citados, inspirada nos trabalhos genealógicos de Michel Foucault, quando um modo de explicar o comportamento humano é muito bem sucedido no presente, seu passado é esquecido. Quando o trauma se generaliza a tal ponto que eventos de caráter tão diverso são etiologicamente equiparados, cabe questionar por sua origem histórica direcionando a reflexão crítica para o tema ancestral, mas segundo a filósofa Susan Neiman (2009), incontornável que é o sofrimento humano.

\section{1-TRAUMA E NARRAÇÃo}

A ligação entre o ato de narrar e a experiência traumática pode ser remontada ao século XIX. O filósofo Ian Hacking (2000) aponta que Pierre Janet e Freud empregaram métodos psicoterapêuticos com finalidade de trazer à tona eventos esquecidos porque experimentados com perturbadora intensidade. Apesar de explicitamente rivais na explicação do funcionamento psíquico, ambos usaram a hipnose para tratar condições patológicas etiologicamente ligadas a certos conteúdos mentais relacionados a quadros com sintomas histéricos. Freud, ainda no final do século XIX, propôs como método de cura a "ab-reação" que articulava, hipnose e catarse afetiva, destacando que "é na palavra que o homem encontra um substituto para ação" (FREUD apud LAPLANCHE; PONTALIS, 1980, p. 22). A ação referida seria aquela em que o indivíduo diante do horror despertado por um acontecimento traumático não foi capaz de levar a cabo.

Segundo Lapalanche e Pontalis (1980), ainda nos primórdios da obra freudiana, se aventa a hipótese de que um acontecimento traumático possa ser inserido dentro de uma cadeia significativa sem o uso da hipnose, apenas por sua associação com outras memórias. A narração do evento teria, portanto, o mesmo efeito curativo da ab-reação. Com o amadurecimento da teoria da sexualidade, 
Melo e Ribeiro (2008) apontam o surgimento não apenas de uma, mas de diversas, teorias do trauma dentro própria da obra freudiana, que serão recuperadas e revisadas por discípulos próximos, como Sandor Ferenczi e Douglas Winnicott.

Com a eclosão da Primeira Grande Guerra, o trauma foi tematizado também fora da clínica. O campo de batalha, orientado pela situação das trincheiras, alarmes, disparos de bombas terrestres e aéreas desencadearia o que Walter Benjamin (2008) chamou de "pobreza da experiência". O filósofo fala em dois tipos de experiências: uma privada e somente acessível àquele que a vivencia e outra que se dá no intercâmbio discursivo pela narração (BENJAMIN, 2000). As condições ultra estimulantes da Guerra comprometeria a passagem da primeira para a segunda, processo essencial para tornar as sensações interiores em elementos psíquicos estáveis. Ainda que a palavra não seja o único elemento que permita o compartilhamento de experiência, a arte de narrar, segundo Benjamin (2008), é um de seus domínios mais desenvolvidos e importantes. É na ausência de estórias e histórias sobre a Guerra, entre outros importantes fenômenos, que Benjamin (2008) encontra fundamento para seu diagnóstico da cultura moderna como espaço-tempo veloz onde a informação circula de modo a obstruir a possibilidade de narrar.

Modry Eksteins (1991), historiador da Primeira Guerra mundial, afirma que o ambiente da Guerra favorecia uma condição subjetiva de encapsulamento e distanciamento do mundo. Pesquisando diversos relatos de soldados, o historiador encontrou mais descrições de estados emocionais de espanto e êxtase do que propriamente narrativas sobre o exterior. Nesse sentido, o diagnóstico que o psicanalista Sandor Ferenczi fez dos combatentes enfermos psiquicamente corresponderia à condição geral de todo combatente: "a libido recua do objeto para o ego, aumentando o amor a si mesmo e reduzindo o amor objetal ao ponto da total indiferença" (FERENCZI apud EKSTEINS, 1991, p. 273).

Indo ao encontro de Benjamin (2008), o historiador também nota a escassez de relatos escritos por combatentes que estiveram no front. Apesar disso, a partir de 1918, algumas obras começam a ser publicadas, sobretudo na Alemanha, retratando o conflito bélico como ocasião propícia a demonstrações de heroísmo. Não eram exatamente relatos pessoais, mas descrições exemplares da situação de guerra e dos valores que os combatentes deveriam exaltar, como honra, sacrifício e patriotismo. O sofrimento do combatente era geralmente reconhecido por intelectuais, como foi o caso do escritor E. C. Cummings. Este autor, nota Ekstein, expressa pessoal e publicamente sua desolação com os "grandes valores" quando passa a assinar seu nome com letras minúsculas.

Segundo Eksteins (1991), um retrato bastante diverso, surge no ano de 1929, com a publicação do romance do ex-combatente Erich Maria Remarque, "Nada de novo no front". Refletindo sobre o absurdo das situações vivenciadas pelos soldados, a obra aponta o panorama de inutilidade da guerra, a falta de perspectiva e sentido como a condição psicológica predominante. No mesmo ano, é publicado uma obra que SeligmaNn-Silva (2009) considera inaugural do ponto de vista historiográfico por se basear inteiramente nos testemunhos dos soldados: Témoins de Jean Norton Cru. 


\title{
2) Dois Modelos de trauma
}

No entanto, para os antropólogos Didier Fassin e Richard Rechtman (2009), as condições patológicas dos militares foram predominantemente veladas ao público e seus relatos restritos à escuta psicoterapêutica.

Como ilustração, lembram que o cineasta John Huston finalizou uma trilogia de documentários sobre a Segunda Guerra com uma obra sobre a Mason House, instituição situada em Long Island empregada para o tratamento de combatentes psiquicamente adoecidos. Finalizado em 1946, Let There Be Light teve sua divulgação proibida por mais de 30 anos. Segundo os autores, mesmo dentro da clínica psicanalítica do trauma desenvolvida durante a Segunda Guerra por autores como Sandor Ferenczi, Karl Abraham, Ernst Simmel e Victor Tausk, não se considerava que a Guerra seria causa suficiente para a eclosão de sintomas neuróticos. Em geral, os quadros tratados não eram vistos como reflexo das situações-limite (que mais tarde, filmes como $O$ franco atirador ou Platoon e, sobretudo, Apocalypse Now irão sublinhar em relação à Guerra do Vietnã). Abraham (apud FASSIN; RECHTMAN, 2009, p. 61-62) é bastante representativo dessa posição, ao se referir aos "neuróticos de guerra" como indivíduos incapazes de sacrifício:

\begin{abstract}
$\mathrm{Na}$ ocasião da guerra, esses homens são colocados sob condições diferenciadas e sob cargas extraordinárias. Eles devem estar preparados todo tempo para sacrificar-se incondicionalmente em prol do bem comum. Isso envolve renúncia a todos privilégios narcísicos. Indivíduos saudáveis são capazes de inibir totalmente seu narcisismo. Assim como são capazes de transferir seu amor, são também capazes de sacrificar seu ego à comunidade. Nesse aspecto aqueles predispostos à neurose ficam para trás dos que apresentam boa.
\end{abstract}

Para a historiadora da ciência Ruth Leys (2008), a narração de experiências traumática ganhará maior publicidade pelo jogo/ tensão entre dois modelos de trauma. Para distinguir modelos de trauma, a autora parte de uma leitura da teoria freudiana do trauma na qual a identificação é o processo psíquico de maior importância. A partir dessa interpretação, Leys frisa que existe uma perpétua tensão entre um modelo mimético e outro anti-mimético. No modelo mimético, o trauma é produzido por uma situação violenta a ponto de obstruir o processo de assimilação psíquica. Paralisado pelo espanto, o indivíduo permanece inteiramente dentro da cena, sem conseguir o distanciamento suficiente entre sujeito e objeto, entre interno e externo, para que possa representá-la.

Nessa condição, se experimentaria uma angústia ligada à sensação de não mais existir. Então, o modelo mimético dirá que se regride a um estado de profundo desamparo, no qual ocorrerá um tipo de identificação bastante primitiva próxima à imitação cega que se dá em estados hipnoides. Devido a esse estado de diminuição de atividade psíquica, a cena não é assimilada plenamente, retornando sob a forma de comportamentos imitativos da cena originária, pesadelos 
ou então imagens repentinas que assaltam à consciência. O psicanalista Ernst Simmel (apud SELIGMANN-SILVA, 2009, p. 1) tentou assim descrever o aspecto intrusivo das imagens traumáticas: "A luz do flash do terror cunha/estampa uma impressão fotograficamente exata". Pode-se dizer que a experiência não se dá como memória. Ao contrário, se dá como percepção, como se estímulos exteriores estivessem naquela ocasião posterior imediatamente chegando ao aparelho psíquico com intensidade esmagadora.

Aplicado a situações onde há violência provocada por agentes humanos, esse modelo tende a desacreditar a narração de eventos traumáticos. Isto se explicaria pelo fato de o modelo mimético enfatizar um narrador psiquicamente entretecido com seu agressor. Uma ilustração bastante curiosa, mas pertinente é dada por Leys (2008) no campo do interrogatório sob tortura. Por exemplo, até a década de 1960 a Agência americana de informações (CIA) produziu manuais que recomendavam o uso de hiper estimulação, voltados para a produção de fadiga e desorientação, com a finalidade obter informações fidedignas em condições de tortura. Posteriormente, o método é questionado porque a situação de extremo desamparo induziria uma identificação com o agressor, tornando qualquer informação dada como suspeita. Se o torturado se identificava com o torturador, ele agiria para agradá-lo, relatando situações que não eram verdadeiras. Segundo Melo e Ribeiro (2006), esse modelo está igualmente presente na obra de Ferenczi, sobretudo em seus estudos sobre abuso sexual. A criança quando abusada sexualmente por um adulto em que confiava tende a negar o acontecimento. Seu relato não seria, portanto, fidedigno em relação à situação traumática. Caberia perfeitamente à clínica psicanalítica acolhê-lo, mas sua divulgação pública não teria sentido.

Tanto Leys (2008) quanto Fassin e Rechtman (2009) apontam uma mudança na relação entre trauma e narração lentamente instalada no período posterior à Segunda Guerra Mundial. Usando a terminologia da autora, a tensão entre modelos de trauma se resolverá em direção ao modelo anti mimético. Nesse modelo, o trauma também é compreendido pelo mecanismo de imitação, porém entendido de modo diferente. A experiência emocionalmente perturbadora é igualmente apontada na gênese das condições traumáticas, no entanto ela não dispara um processo de imersão na cena, mas um alheamento totalmente em relação ao acontecimento. Em outros termos, enquanto no outro modelo, o distanciamento é insuficiente, neste, o distanciamento é excessivo. No modelo mimético, o indivíduo passa pela experiência apavorante de indistinção entre si e mundo externo, no anti-mimético, há, forçando o contraste, a experiência absolutamente passiva onde o indivíduo observa a si mesmo. Então, Leys (2008) conclui que a narração da experiência traumática tende a ser validada nesse último modelo, pois sujeito e objeto estão numa posição onde é possível haver a distância necessária ao conhecimento do exterior. Ainda que as memórias traumáticas possam ser consideradas imensamente perturbadoras e extremamente fragmentadas, a atividade do evento confrontada à passividade do sujeito abre terreno para um tipo de narrativa realista, por não se estar comprometido pela identificação com o agressor. 
Um quadro denominado "síndrome do sobrevivente" (que ganhará muita força na década de 1960) une tanto traços de configuração anti-mimética quanto de traços de configuração mimética (LEYS, 2008). Os estudos que levaram à essa classificação surgem relacionados à situação psíquica do sobrevivente dos campos de concentração. Segundo Fassin e Rechtman (2009), o psicanalista Bruno Bettelheim publicou os primeiros escritos sobre o tema. Bettelheim vivenciou essa condição como ex-prisioneiro de Dachau e Buchenwald nos anos 1938-1939, conseguindo escapar e imigrar para os Estados Unidos, onde inicia pesquisas sobre seus efeitos traumáticos. Nota com frequência um imenso e desolador sentimento de culpa entre os sobreviventes, que encaram sua sorte como resultado do sacrifício da vida de outrem. A libertação dos campos de concentração ao invés de ser vivenciada como um retorno à vida, instala a dúvida quanto ao próprio caráter e mérito por ter escapado ao destino de milhões. Na absoluta aleatoriedade da morte, que se furta a qualquer explicação, a busca do sentido se faz obrigação incontornável para o sobrevivente. O problemático é que tal aleatoriedade cancela a priori qualquer coerência narrativa (LIFTON, 2005)

Embora frise o impacto do evento exterior sobre um sujeito passivo, Bettelheim, segundo Leys (2008) ainda trabalha a partir do modelo mimético do trauma. A sintomatologia típica da síndrome do sobrevivente seria uma culpa atordoante e injustificada pelo destino diferenciado. A explicação desse sentimento se dava a partir da regressão a um estado de identificação com o agressor. Como resultado, a vítima experimenta um vínculo ambíguo de amor e ódio pelo seu carrasco, enxergando a si mesmo com características alheias. Imagina-se agressivo, ainda que imensamente desamparado. No momento seguinte, a violência que acredita possuir é inconscientemente voltada para seu interior Ao final, se transforma em culpa, ou seja, é traduzida como ódio por si mesmo.

\section{3- A Crítica À "SíndRome do SObReVIVENTE"}

A teoria de Bettelheim será muito importante na clínica psiquiátrica do trauma americana da década de 1970 . Um dos principais autores a expandir sua teoria para contextos distintos dos campos de concentração foi Robert Jay Lifton (2005), que realizou extensas pesquisas com os sobreviventes da bomba de Hiroshima chegando a conclusões semelhantes. O autor, que em artigo recente afirmou que os americanos, todos sem exceção, devem ser considerados sobreviventes em virtude do atentado terrorista às torres gêmeas em 2001, buscou também investigar os mecanismos comportamentais que favoreceriam a sobrevivência em situações-limite.

A partir dos estudos de Fassin e Rechtman (2009), Hacking (2000) e de Leys (2008), pode-se dizer que a contribuição de Lifton para a predominância de um modelo anti-mimético reside em duas instâncias. Em primeiro, por articular em seus estudos os mecanismos intra-psíquicos com condições objetivas que acabam sendo melhor especificadas em seu funcionamento. As chamadas situações limites estão ligadas, como igualmente sublinhou a filósofa Hannah Arendt, não tanto à extensão dos assassinatos, mas à sua aleatoriedade, que as tornam imper- 
meáveis a explicações racionais. Em segundo lugar, Lifton desenvolve pesquisas a partir de entrevistas com sobreviventes, nas quais a expressão do sofrimento está referida a acontecimentos coletivos e objetivos. O próprio sintoma de culpa intensa é uma evidência de que o indivíduo vivenciou situações desumanizadoras (FASSIN; RECHTMAN, 2009). Com Lifton, a clínica do trauma vai do sintoma ao acontecimento, enquanto uma geração anterior realizava o movimento contrário, indo da Guerra ao, por exemplo, narcisismo.

Endossando a necessidade de se narrar publicamente vivências traumáticas, as demandas formuladas por movimentos sociais se funde ao tipo de abordagem empregado por Bettelheim e Lifton. Este último relata como foi procurado por organizações de sobreviventes dos campos de concentração para expandir a importância dos testemunhos, que já havia se destacado no julgamento de Eischman em Israel Enquanto no imediato pós-guerra, predominavam depoimentos escritos como peças jurídicas usadas contra nazistas, esse julgamento foi marcado pela presença das vítimas e por relatos dentro do tribunal (VAZ, 2010).

Torna-se importante nesse momento, usar a memória contra a repetição do passado (HACKING, 2000). O cineasta Uli Edel, no filme O grupo Baader-Meinhof, frisa a generalização do holocausto como modelo de exploração humana. No relato do filme, fica claro que o grupo se configura inicialmente contra a Guerra do Vietnã entendendo-a como um segundo Holocausto.

Segundo Leys (2008), essa mesma geração se sente de tal forma impelida a dar credibilidade aos depoimentos dos sobreviventes a ponto da própria categoria de "síndrome do sobrevivente" se tornar questionável. Nesse momento, o modelo anti-mimético do trauma ganhará mais um terreno contra o modelo mimético. O objetivo de várias críticas dirigidas à noção de "culpa do sobrevivente" é retirar todo e qualquer peso do indivíduo sobre seu sofrimento. Aquele que foi poupado das máquinas de destruição do século XX não sofre pelo ódio que dirige a si mesmo, mas simplesmente porque o fizeram sofrer. Qualquer explicação que se demore muito em vetores intermediários entre o agressor e o sofredor será considerada imoral por ampliar a dor da vítima (VAZ, 2010). Leys (2008) cita a crítica de Terence De Pres dirigida diretamente a autores como Lifton e Bettelheim: "Nós estamos em meio a uma conspiração do silêncio e retiramos a autoridade do sobrevivente definindo-a pela culpa. Se ele é culpado, talvez então seja verdade que as vítimas da atrocidade colaboraram para sua própria destruição" (DE PRES apud LEYS, 2008, p. 62).

\section{4- Clínica do trauma e movimentos sociais}

No cenário americano dois movimentos sociais em particular tiveram suas trajetórias intensificadas pela clínica psiquiátrica do trauma (FASSIN; RECHTMAN, 2009). Primeiramente, na década de 1960, o movimento feminista se voltou fortemente para a temática do abuso sexual. Pela compreensão sócio-histórica empregada, o índice superior de crianças do sexo feminino entre as vítimas estava relacionada profundamente ao patriarcalismo da sociedade. Se o poder se concentrava em torno dos membros masculinos da família, a autoridade sobre bens e 
nas deliberações poderia facilmente deslizava para o corpo e sexualidade feminina. Reverter essa configuração histórica passaria pela denúncia pública do abuso, dando voz à vítima. As feministas tiveram sucesso na mobilização de profissionais clínicos como pediatras e radiologistas que eram capazes de mostrar as marcas físicas da violência. Porém, esbarraram na questão de não haver provas objetivas para as feridas invisíveis impressas no psiquismo das vítimas. Demonstrar essas marcas também implicaria em revelar nexos causais entre passado e presente, já que muito das vítimas de abuso infantil eram agora adultas (VAZ, 2010).

Como afirma Leys, jamais houve momento histórico em que um dos modelos de trauma desaparecesse, estes sempre conviveram com diferentes ênfases. Não basta, portanto, remontar às teorias psicológicas do trauma, é preciso ampliar o escopo para os atores interessados em que uma das versões se tornasse proeminente.

A demanda do movimento feminista encontrou na clínica psiquiátrica do trauma bases clínicas para sua crítica social. Afirmar que as vítimas sofrem em silêncio, que não se pronunciam porque se dividem entre a sua dor e o ponto de vista do agressor, foi um mecanismo importante para superar o problema do hiato temporal. O silêncio seria sinal do segredo. Por outro lado, o estudo de autores como Lifton sobre as situações desumanizadoras, foram interessantes para o movimento em defesa dos ex-combatentes do Vietnã. Como já havia sido notado, ao final da década de 1960, o Holocausto estava se tornando modelo de compreensão para diversos tipos de regimes e situações totalitárias (FASSIN; RECHTMAN, 2009). A Guerra do Vietnã foi interpretada nessa chave não somente como massacre imposto aos vietnamitas, mas também em relação aos combatentes enviados contra vontade própria. $\mathrm{O}$ estado americano deveria, então ser responsabilizado pela morte e sofrimento de milhares de sobreviventes.

Neste momento, a clínica do trauma começou a se dirigir para outro fenômeno: a agressividade dos combatentes. Até então, o fenômeno majoritariamente estudado estava ligado à vítima evidente de uma agressão, mas o algoz não tinha ainda recebido a mesma atenção. As teorias se expandiram para os efeitos psicológicos de situações adversas sobre o comportamento de combatentes envolvidos em extermínio de aldeias como May Lai. A partir de entrevistas, foi sugerido um retrato bastante diferente do esperado. Esses militares teriam conduta e caráter à prova de dúvida, criando vínculos profundos de solidariedade entre si. Ao ver seus companheiros abatidos, eles reagiam exageradamente. Corroborava a hipótese, as entrevistas terem revelado que aqueles que se recusaram a participar dos ataques aos vietnamitas não tinham vínculos grupais fortes.

Essa explicação estimulava a empatia dos não militares com os combatentes e, a contraluz, depositava a responsabilidade pelo sofrimento coletivo no Estado americano, que passou a indenizar financeiramente os ex-combatentes traumatizados. 


\section{5- Estresse PóS-TRAUMÁtico E NARRAÇÃo do SOFRIMENTO.}

Um passo fundamental para que essa indenização se tornasse procedimento corrente foi dado pela força-tarefa psiquiátrica responsável pela elaboração da terceira versão do DSM. Os principais responsáveis pelas pesquisas compartilhavam pelo menos duas ambições: dar fundamento clínico para que os ex-combatentes traumatizados pudessem ser financeiramente ressarcidos e criar um sistema classificatório mais objetivo, centrado na descrição dos sintomas ao invés de em sua explicação. Enquanto nas versões exteriores, predominava o vocabulário psicanalítico expresso no campo traumático como "neurose de guerra", novas nomenclaturas recobriram o campo.

Uma expressão desse esforço foi a inclusão do "Transtorno de Estresse pós-traumático", apontado em uma pesquisa extensa realizada em 1995 com sendo a quinta enfermidade mental com maior prevalência nos Estados Unidos (KESSLER, et al, 1995). No Brasil, tanto no campo emergente da psicologia das emergências, há preocupações em se delimitar sua prevalência e tratamento adequado (CONSELHO FEDERAL DE PSICOLOGIA, 2011), quanto estudos de neuro-imagem que revelam modificações estruturais e funcionais em sistemas ligados às memórias emocionais (PERES, 2009). Pode-se notar demandas para o desenvolvimento de pesquisas, usando-se argumentos ligados a alta taxa de criminalidade urbana e óbitos por acidentes de trânsito (FIGUEIRA; MENDOWLICZ, 2003). Mas o que talvez seja mais interessante aqui destacar é que a introdução do TEPT expandiu a compreensão do que se considera evento traumático e o papel desses eventos na eclosão dos sintomas.

São três tipos de critérios considerados: em primeiro, a experiência direta ou indireta de um evento estressor; em segundo distúrbios da memória, como amnésia e hipermnésia e uma suscetibilidade exacerbada a estímulos que disparam reações de fuga e enfrentamento, e terceiro, o evitar fóbico de situações que podem suscitar reações de alarme (GROHOL, 2014). O primeiro critério não apresenta uma definição precisa do que seria um evento estressor. Na primeira versão, são mencionados acontecimentos súbitos e violentos, que incluem desde assaltos até catástrofes naturais. Na segunda versão do TEPT, apresentada no DSM-IV na década de 1990, incluem-se como critérios a resposta emocional aos acontecimentos. Deste modo, um evento relativamente banal, destaca o DSM-IV-R, como ser informado sobre óbitos de parentes poderia ser incluído como evento estressor desde que seja recebido com intensidade emocional. Na versão mais recente do DSM, lançada em 2013, são retirados os aspectos subjetivos de resposta emocional e os critérios tornam-se novamente estritamente objetivos (GROHOL, 2014).

Trata-se de uma concepção do trauma anti-mimética, na medida em que separa claramente um sujeito passivo e um evento disruptivo. A noção de culpa do sobrevivente que ainda permanecia no DSM-III, tornou-se secundária em sua revisão publicada em 1987 (LEYS, 2008). Embora, o escopo psicanalítico que garantia um espaço para o processo de identificação tenha sido retirado, o DSM em sua terceira versão em diante é considerada por Leys um modelo anti-mimético por separar etiologicamente sujeito e objeto. Como efeito, a narração do 
sofrimento traumático que já havia sido valorizada a partir do movimento feminista torna-se inteiramente habilitado, apesar das memórias traumáticas serem tomadas como fragmentárias. Hacking (2000) nota que o retorno de imagens do evento traumático é considerado uma prova da inscrição desse acontecimento no psiquismo. Essa observação é validada em um caso de perícia psiquiátrica realizado no Brasil. O fato do demandante de indenização, um militar que participou de operações militares na República Dominicana, ter relatado com clareza suas memórias invalidou o diagnóstico de TEPT (MENDLOWICZ; BERGER, 2011).

Com a separação clara entre sujeito e evento traumático embutida na categoria de TEPT, as narrações de experiências traumáticas têm adquirido maior credibilidade. O filósofo Paulo Vaz (2010), a partir de pesquisa extensa sobre a narrativa midiática tanto em semanários impressos e telejornais, propõe que a forma narrativa para o sofrimento traumático está ligada à compaixão. Hannah Arendt (2001) estabelece uma diferença entre compaixão e piedade a fim de apreender o posicionamento dos que não sofrem frente ao sofrimento alheio. A compaixão tem na crucificação de Cristo seu protótipo; trata-se de uma exposição ou narração de um sofrimento único, fortemente individualizado. Já na piedade, o sofrimento representado tem caráter exemplar, pois pretende ser a representação de uma realidade coletiva.

Comentando a narração midiática das fortes chuvas que assolaram a região de Angra dos Reis em 2010, o filósofo nota uma representação individualizada do sofrimento, onde são relatados detalhes pessoais da vida das vítimas, seus hobbies e vínculos afetivos e projetos inconclusos. As referências ao sofrimento traumático aparecem tanto sob a forma de distúrbios da memória, como pesadelos, como invasão do passado no presente apagando a perspectiva de futuro. $\mathrm{O}$ relato é feito a partir da perspectiva das vítimas frequentemente fotografadas em expressões emocionais de desespero.

Há um efeito indiretamente terapêutico quando as notícias denunciam a irresponsabilidade das autoridades, frisando sua inépcia na gestão de riscos. Visa-se que essa memória narrada e divulgada no espaço público impeça que novos desastres ocorram. As entrevistas conduzidas pelo historiador Michael Pollak (2010) com vítimas do Holocausto são mais diretamente articuladas à terapêutica. O autor afirma que é somente através desses depoimentos que a subjetividade da vítima pode ser reconstruída. Criticando as teorias de Lifton e Bettelheim, o historiador afirma que a experiência de condições desumanas afeta o psiquismo sempre de modo individual e não há como determinar que a culpa é o que articula a condição psíquica dos sobreviventes.

No terreno cinematográfico, o polêmico Shoah de Claude Lanzmann e o mais recente $A$ imagem que falta do cambojano Rithy Pahn apresentam características da forma compassiva de narração. O primeiro é um estudo pormenorizado da dificuldade de narrar o Holocausto, mas que insiste em sua possibilidade, recolhendo testemunhos de sobreviventes. Com mais de nove horas de duração, Shoah alterna silêncios com paisagens que nada mais aparentam do cenário destrutivo do passado. Diante desse enorme apagamento histórico que é mostrado, 
é enfatizada a importância do relato em primeira pessoa. Ainda que o acontecimento seja impossível de plena representação, a estrutura fragmentada do filme busca ser fiel à forma ilógica, irracional do acontecimento. A impossibilidade de representar não cancela a busca da representação, mas a move por caminhos não lineares, não linearidade própria à experiência traumática.

A imagem que falta se refere ao genocídio conduzido pelo Kmher vermelho entre 1976-1979, que resultou na morte de aproximadamente dois milhões de cambojanos. $\mathrm{O}$ autor vivenciou ainda no início da adolescência, os eventos que busca resgatar a partir da narrativa cinematográfica. Essa recorre a um recurso poético, usando pequenas miniaturas feitas de madeira para compor cenários de uma memória nebulosa que vai ganhando seus contornos com o desenvolvimento narrativo. Alternam-se essas imagens estáticas com cenas documentais produzidas pelo regime totalitário com a finalidade de mostrar a adesão da população, que apesar de apresentar movimento, se mostram extremamente automáticas. Curiosamente, as cenas estáticas formadas por cenários artesanais com peças de madeira comparativamente aparentam mais vitalidade. Esse recurso é usado para dar conta da ausência de registro imagético, bem como suplementar a memória com a atividade manual que resultou nos cenários estáticos. A memória é artesanalmente forjada, sem que isso comprometa sua autenticidade. Pelo contrário, na narrativa da compaixão, a memória pode ser criada e ser verdadeira ao mesmo tempo.

\section{CONSIDERAÇõES FINAIS}

O percurso aqui traçado envolve diversos atores sociais e teorias acerca do trauma, resultando na predominância de um modelo anti-mimético. Tal modelo enfatiza a fragilidade humana perante acontecimentos externos, permitindo a distância necessária para uma narração da experiência traumática.

Roger Luckhurst (2003) nota alguns paradoxos envolvidos nessa narração. Ao supor um "sujeito traumático", a narração do sofrimento se dá a partir da premissa de que esse sujeito é faltoso, impossível e fragmentado. $\mathrm{O}$ autor diagnostica uma espécie de "traumatofilia" na extensa publicidade que alguns relatos de experiências traumáticas adquirem. Seria fundamentalmente arriscado articular trauma e narração em primeira pessoa, na medida em que a legitimação do sofrimento das vítimas se dá a partir de um evento externo que encontra um indivíduo passivo. Narrar de modo compassivo o sofrimento traumático recorre a enunciados clínicos que descrevem a condição humana pelo sofrimento de emoções profundamente perturbadoras.

E, sobretudo, a etiologia vaga e ampla do TEPT expande a possibilidade de sofrer a todo indivíduo. Na visão de Paulo Vaz (2010), essa etiologia contribui para a formação de uma condição subjetiva vulnerável tão generalizada, ao ponto de ser capaz de nos tornar vítimas virtuais. 


\section{Nota}

${ }^{1}$ Como observa Michael Rothberg (2000), existem diversos pesquisadores do Holocausto que consideram-no inarrável, usando o argumento que o sujeito do Holocausto não é o sobrevivente, mas os que foram exterminados. No entanto, pode-se dizer que ainda assim, essa linha teórica costuma reconhecer que há verdade na memória dos sobreviventes, ainda que seja, como memória traumática, fragmentada, de difícil acesso, fundamentalmente inacabada. Assim argumentam documentários sobre o genocídio judeu como Shoah ("acidente" em hebraico) de Claude Lanzmann (1985) ou o A imagem que falta, sobre o genocídio cambojano, de Rithy Panh (2013), nos quais se frisa a impossibilidade de resgatar a totalidade do acontecimento.

\section{REFERÊNCIAS}

AMERICAN Psychiatric Association, Diagnostic and statistical manual of mental disorders (DSM-II). 3. ed. Washington DC: APA, 1980.

APOCALYPSE Now. Direção: Francis Ford Coppola. San Francisco: Zoetrope Studios, 1979. 1 DVD.

ARENDT, H. Sobre a Revolução, Lisboa: Relógio D’Água, 2001.

BENJAMIN, W. A modernidade e os modernos. Rio de Janeiro: Tempo Brasileiro, 2000.

BENJAMIN, W. O Narrador. In: Magia e Técnica, Arte e Política. São Paulo: Brasiliense, 2008. Obras escolhidas, v. 1, p. 197-221.

CONSELHO FEDERAL DE PSICOLOGIA. Psicologia de emergências $e$ desastres: promoção de direitos e construção de estratégias na América Latina. Brasiília: CFP, 2011.

EKSTEINS, M. A Sagração da Primavera. Rio de Janeiro: Rocco, 1991.

FASSIN, D.; RECHTMAN, R. The Empire of Trauma: an inquiry in the condiction of victimhood. Princeton: Princeton University Press, 2009.

FIGUEIRA, I.; MENDLOWICKS, M. Diagnóstico do estresse pós-traumático. Revista de Psiquiatria, v. 25, supl.1, p. 12-16, 2003.

FRANCO atirador, O. Direção: Michael Cimino. London: EMI Films, 1978. 1 DVD.

GROHOL, J. M. DSM-5 Resource guide. Disponível em: < http://psychcentral. com/dsm-5/>. Acesso em: 21 jun. 2014.

GRUPO Baader-Meinhof, O. Direção: Uli Edel. Munich: Constantin Film Produktion, 2008. 1 DVD. 
HACKING, I. Múltiplas personalidade e as ciências da memória. Rio de Janeiro: J. Olympio, 2000.

HACKING, I. Ontologia Histórica. Rio Grande do Sul: Unisinos, 2009.

IMAGEM que falta, A. Direção: Rithy Panh. Boulogne: Catherine Dussart Productions (CDP), 2013. 1 DVD.

KESSLER et al. Postttraumatic stress disorder in the National Comordity Survey. Arquive General of Psichiatry, [online], v. 52, n. 12, 1048-1060, 1995.

MELO, M. T.; RIBEIRO, P. C. Modelos do trauma em Freud: e suas repercussões na psicanálise pós-freudiana. Percurso, $2^{\circ}$ sem., p. 37-51, 2006.

MENDLOWICZ, M.; BERGER, W. Simulação de Transtorno de Estresse Póstraumático. Jornal de Psiquiatria, v. 60, n. 1, p. 67-70, 2011.

LAPLANCHE, J.; PONTALIS, J. P. Vocabulário de Psicanálise. São Paulo: Martins Fontes, 1980.

LET there be light. Direção: John Huston. Long Island: U.S. Army Pictorial Services, 1946. 1 DVD.

LEYS, R. From guilty to shame: Auschwitz and after. Princeton: Princeton University Press, 2008.

LIFTON, R. J. Americans as survivors. New England Journal of Medicine, v. 352, n. 22, p. 2263-2265, June 2, 2005. Disponível em: <http://www.nejm.org/ doi/pdf/10.1056/NEJMp058048>. Acesso em: 21 jun. 2014.

LUCKHURST, R. Traumaculture. New Formations, [S.1.], n. 50, p.28-49, 2003.

NEIMAN, S. O Mal no pensamento moderno. São Paulo: Difel, 2009.

PLATOON. Direção: Oliver Stone. Hollywood: Hemdale Film, 1986. 1 DVD.

PERES, J. P. Contribuições das neurociências à psicoterapia. Arquivos Médicos, São Paulo, v. 54, n. 1, p. 31-36, 2009.

POLLAK, M. A gestão do indizível. WebMosaica, v.2, n 1, jan.-jun. 2010. Disponível em: <http://www.seer.ufrgs.br/index.php/webmosaica/article/ view/15543/9299>. Acesso em: 13 jun. 2014.

ROTHBERG, M. Traumatism realism. Minesotta: University of Minesotta, 2000. 
SARLO, B. Tempo passado: cultura da memória e guinada subjetivista, São Paulo: Companhia das Letras, 2006.

SELIGMANN-SILVA, M. Fotografia como arte do trauma e imagem-ação. Fórum Latino Americano De São Paulo, São Paulo, p. 1-23, 2009. Disponível em: $\quad<$ http://www.forumfoto.org.br/wp-content/uploads/2010/09/seligmann fotografia_como_arte_do_trauma.pdf>. Acesso em: 12 jun. 2014.

SHOAH. Direção de: Claude Lanzmann. Paris: Les Films Aleph, 1985. 1 DVD.

VAZ, P. Políticas do sofrimento e as narrativas midiáticas de catástrofes naturais. Revista Famecos, Porto Alegre, v. 18, n. 1, p. 212-234, 2010.

Recebido em: 02 de julho de 2014 Aceito em: 03 de setembro de 2014 